Communication

\title{
Patterned Growth of Horizontal ZnO Nanowire Arrays
}

Sheng Xu, Yong Ding, Yaguang Wei, Hao Fang, Yue Shen,

Ashok K. Sood, Dennis L. Polla, and Zhong Lin Wang

J. Am. Chem. Soc., 2009, 131 (19), 6670-6671• DOI: 10.1021/ja902119h • Publication Date (Web): 29 April 2009

Downloaded from http://pubs.acs.org on May 13, 2009

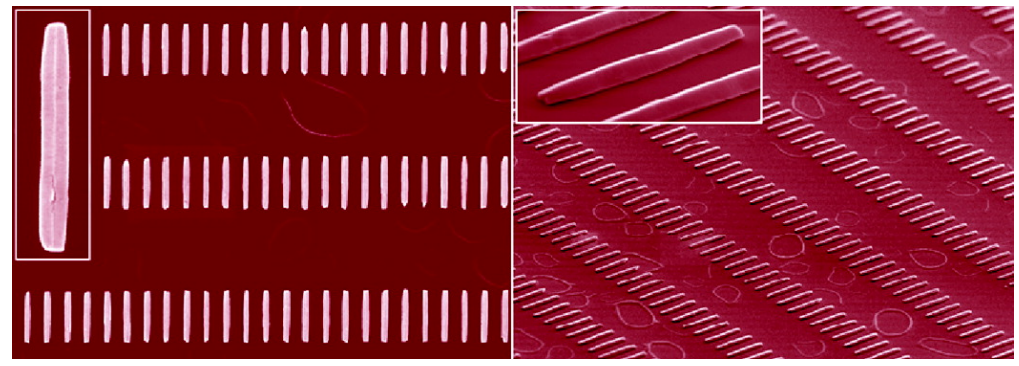

\section{More About This Article}

Additional resources and features associated with this article are available within the HTML version:

- $\quad$ Supporting Information

- $\quad$ Access to high resolution figures

- $\quad$ Links to articles and content related to this article

- $\quad$ Copyright permission to reproduce figures and/or text from this article

\section{View the Full Text HTML}




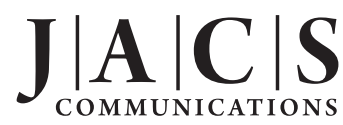

Published on Web 04/29/2009

\title{
Patterned Growth of Horizontal ZnO Nanowire Arrays
}

\author{
Sheng Xu, ${ }^{\dagger}$ Yong Ding, ${ }^{\dagger}$ Yaguang Wei, ${ }^{\dagger}$ Hao Fang, ${ }^{\dagger}$ Yue Shen, ${ }^{\dagger}$ Ashok K. Sood, ${ }^{\ddagger}$ Dennis L. Polla, ${ }^{\S}$ \\ and Zhong Lin Wang*,† \\ School of Material Science and Engineering, Georgia Institute of Technology, Atlanta, Georgia 30332, Magnolia \\ Optical Technologies, Inc., 52-B Cummings Park, Woburn, Massachusetts 01801, and DARPA/MTO,
}

3701 North Fairfax Drive, Arlington, Virginia 22203-1714

Received March 18, 2009; E-mail: zhong.wang@mse.gatech.edu

As an excellent member in the family of one-dimensional nanostructures, $\mathrm{ZnO}$ nanowires (NWs) have found spectacular applications in fabricating electronic, optoelectronic, electrochemical, and electromechanical devices, such as ultraviolet (UV) lasers, ${ }^{1}$ light-emitting diodes, ${ }^{2}$ field emission devices, ${ }^{3,4}$ solar cells, ${ }^{5}$ and piezo-nanogenerators. ${ }^{6,7}$ In an effort to integrate the ZnO NWs into a more regular form to enhance the performance of the nanodevices, a variety of techniques have been employed to fabricate patterned vertically aligned $\mathrm{ZnO} \mathrm{NW}$ arrays, including photolithography, ${ }^{8}$ nanosphere lithography, ${ }^{9,10}$ nanoimprint lithography, ${ }^{11}$ and electron beam lithography (EBL). ${ }^{12}$ As a counterpart of the vertically aligned $\mathrm{ZnO} \mathrm{NW}$ arrays, horizontally aligned $\mathrm{ZnO} \mathrm{NW}$ arrays have also been grown by a few approaches, such as growing $\mathrm{ZnO}$ NWs out of prepatterned side walls of a thin $\mathrm{ZnO}$ seed layer or metal catalysts on planar alumina substrate by hydrothermal decomposition, ${ }^{13}$ physical vapor deposition, ${ }^{14-16}$ or metal-organic chemical vapor deposition. ${ }^{17}$ But the horizontal NWs were rather sparse and random in horizontal orientation ${ }^{14,17}$ or of a poor horizontal alignment. ${ }^{13,15,16}$ Horizontal alignment of the $\mathrm{ZnO} \mathrm{NWs}$ after growth were also achieved by dispersing the NWs into solvents and then applying a high frequency alternative electrical field. ${ }^{18}$

In this study, we report a technique for horizontal growth of patterned $\mathrm{ZnO} \mathrm{NW}$ arrays by the hydrothermal decomposition method. The $\mathrm{ZnO}$ NWs were epitaxially grown onto the [2 $\overline{1} \overline{1} 0]$ surface of a single crystal $\mathrm{ZnO}$ substrate. After spin coating the substrate with a thin layer of polymethyl methacrylate (PMMA), the strip shape areas to be grown with $\mathrm{ZnO}$ were defined by EBL along the $\langle 0001\rangle$ direction of the substrate so that they were directly exposed to the nutrient solution. The hydrothermal decomposition was conducted at a low temperature $\left(<100{ }^{\circ} \mathrm{C}\right)$ for $2.5 \mathrm{~h} .{ }^{19}$ The detailed experimental procedure is elaborated in the Supporting Information (SI).

As illustrated in Figure 1a,b, growing out of an array of stripe areas of $2 \mu \mathrm{m}$ by $400 \mathrm{~nm}$ each, with the long axis parallel to the $\langle 0001\rangle$ direction of the substrate (see SI Figure S1 “i”), the $\mathrm{ZnO}$ NWs are uniform in length and width. However, as is always the case for synthesizing $\mathrm{ZnO}$ NWs by wet chemical methods, there is a lateral expansion of the $\mathrm{ZnO} \mathrm{NWs}$ once they grow out of the photoresist holes. ${ }^{12,20}$ The NWs are $\sim 6 \mu \mathrm{m}$ in length and $800 \mathrm{~nm}$ in width. To put it in a different way, the dimensions of the $\mathrm{ZnO}$ NWs grown by wet chemical methods are not only decided by the physical confinement from the photoresist but also in fact established by the growth parameters/rates, such as the precursor concentration, the growth temperature, and growth time. Generally speaking, low precursor concentration, high growth temperature, and moderate growth time favor thin and high aspect ratio NWs;

Georgia Institute of Technology.

Magnolia Optical Technologies, Inc.

DARPA/MTO.
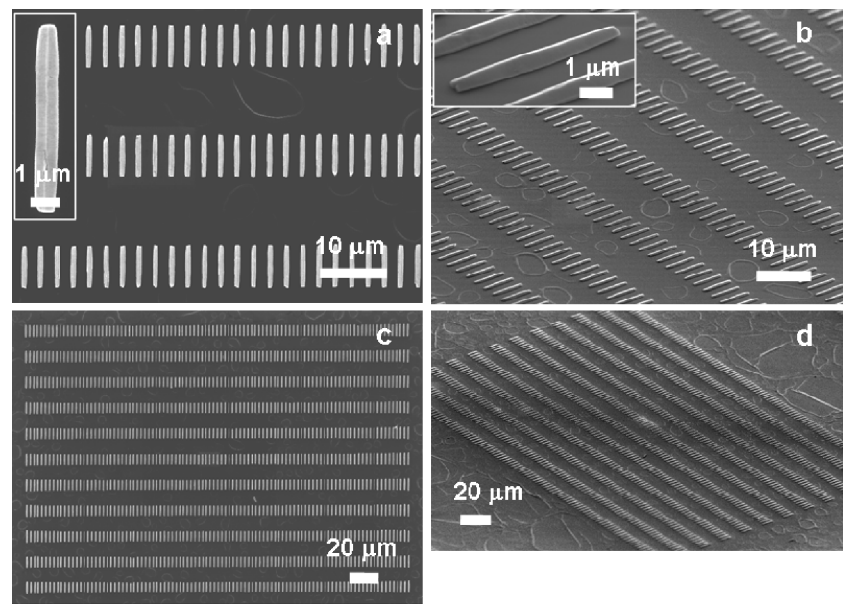

Figure 1. (a) Top view and (b) $60^{\circ}$ tilt view of the patterned horizontal $\mathrm{ZnO} N W$ arrays that were grown by fabricating stripe areas along the $\langle 0001\rangle$ direction on the substrate. Insets are enlarged images. The NWs may be enclosed by $\{01 \overline{1} 0\}$ facets. (c) Top view and (d) $60^{\circ}$ tilt view of an array of dimensions $200 \mu \mathrm{m}$ by $300 \mu \mathrm{m}$.

low precursor concentration, low growth temperature, and too long or too short growth time is inclined to produce thick and low aspect ratio NWs. ${ }^{21}$ The patterned horizontally aligned $\mathrm{ZnO} \mathrm{NW}$ arrays could be straight forwardly scaled up for any practical applications. As shown in Figure 1c,d, a $200 \mu \mathrm{m}$ by $300 \mu \mathrm{m}$ pattern could be generated by EBL in $\sim 5 \mathrm{~min}$.

Even though there is a significant lateral expansion of the $\mathrm{ZnO}$ NWs once they grow out of the photoresist openings, we can still control the dimensions of the NWs responsively and effectively. As we can see in Figure 2a, the top row of $\mathrm{ZnO} \mathrm{NWs}$, with an average diameter of $800 \mathrm{~nm}$, grew out of an array of $2 \mu \mathrm{m}$ by 400 $\mathrm{nm}$ openings while the bottom row of $\mathrm{ZnO}$ NWs, with an average diameter of $400 \mathrm{~nm}$, grew out of an array of $2 \mu \mathrm{m}$ by $200 \mathrm{~nm}$ openings. Under the current hydrothermal growth parameters, the widths of both rows of NWs are approximately two times the size of the photoresist confinements. In addition, both rows of NWs have almost the same $7.5 \mu \mathrm{m}$ length that is approximately four times the size of the photoresist openings. ZnO NW arrays of various dimensions and aspect ratios could meet different application purposes. The initial width of the NW in contact with the substrate could be defined by the size of the open stripe, but lateral expansion is overwhelmed as the growth proceeds.

For wurtzite structured $\mathrm{ZnO}$ NWs, they have intrinsic high energy $\pm(0001)$ polar surfaces terminated with a $\mathrm{Zn}^{2+}$ plane and an $\mathrm{O}^{2-}$ plane, respectively. These surfaces have high energy and active sites, which the newly arrived precursor molecules are more likely to adsorb to, resulting in fast growth along $\langle 0001\rangle$. The NWs shown 


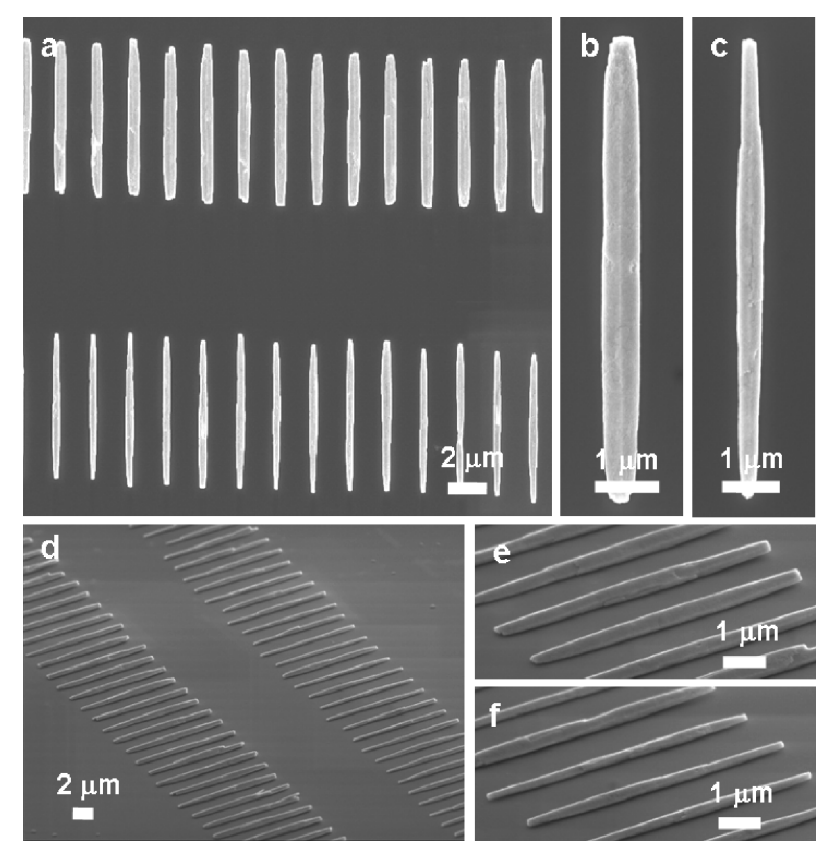

Figure 2. Illustration of varying the width of the horizontal $\mathrm{ZnO}$ NW arrays. (a) Top view of the thick $\mathrm{ZnO} N W$ arrays (top row) growing out of $2 \mu \mathrm{m}$ by $400 \mathrm{~nm}$ openings and thin $\mathrm{ZnO} \mathrm{NW}$ arrays (bottom row) from $2 \mu \mathrm{m}$ by $200 \mathrm{~nm}$ openings. Enlarged top view of (b) a thick and (c) a thin NW. (d) $60^{\circ}$ tilt view of the NW arrays and enlarged (e) thick and (f) thin NWs
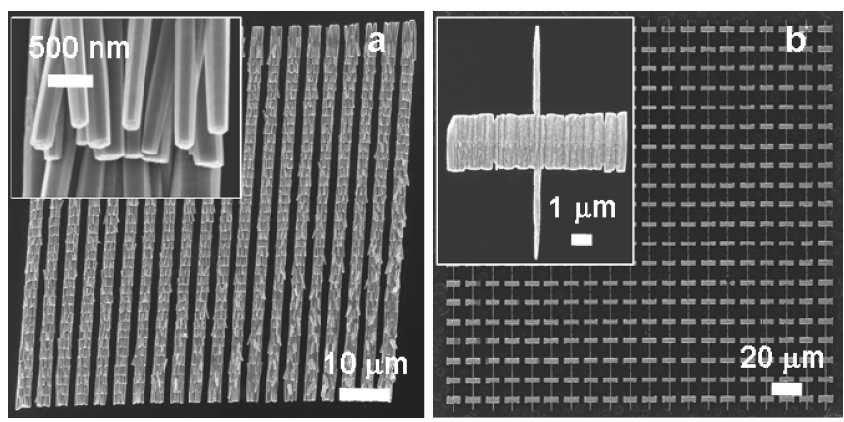

Figure 3. (a) Top view image of $\mathrm{ZnO} \mathrm{NW}$ arrays growing out of strips perpendicular to the $\langle 0001\rangle$. (b) Top view image of $\mathrm{ZnO} N W$ arrays growing out of an array of cross-arm openings parallel and perpendicular to $\langle 0001\rangle$. Insets are enlarged images.

in Figure 1 are along $\langle 0001\rangle$, which were formed by a single-nucleus growth process.

The growth morphology of the NWs depends on the quality and structure of the substrate. Although $\langle 0001\rangle$ stripe areas can be defined by EBL, a small miscut of the substrate along $\langle 0001\rangle$ results in terrace along this direction. In such a case, the step edges with the (0001) facets can be the "mini" substrates for the growth. A direct growth of multiple NWs out of the step edges formed unidirectionally piled parallel NWs, as shown in Figure 3a. This was a multinuclei growth process.

Alternatively, for a case in which the substrate was prepared with little or no miscut off [2 $\overline{1} \overline{1} 0]$, a cross-arm shaped opening pattern was first created by EBL on the substrate. The stripes parallel to $\langle 0001\rangle$ led to the formation of individual NWs owing to a singlenuclear growth process, while the stripes perpendicular to $\langle 0001\rangle$ resulted in closely packed NW growth due to a multinuclei growth process, as shown in Figure 3b. Importantly, the lengths at the two sides of the perpendicular stripe were approximately equal (the inset image in Figure 3b), indicating that the growth rates along $\mathrm{Zn}$ - terminated [0001] and O-terminated [0001] were approximately the same. This indicated that the catalytic activities of the two polar surfaces were approximately the same for hydrothermal growth.

In summary, we have demonstrated an approach for growing horizontally aligned $\mathrm{ZnO} \mathrm{NW}$ arrays by hydrothermal decomposition at a temperature lower than $100{ }^{\circ} \mathrm{C}$. The horizontal $\mathrm{ZnO} \mathrm{NW}$ arrays are epitaxially grown on single crystal $\mathrm{ZnO}(2 \overline{1} \overline{1} 0)$ surfaces and are rather uniform in length and width. Although the NWs suffer from a lateral expansion once they grow out of the photoresist confinements, we can still adjust the dimensions of the NWs accordingly. Because of the anisotropic growth habits of the wurtzite $\mathrm{ZnO}$ NWs, we should also be insightful about the manipulation and control over orientation of the photoresist openings relative to the substrate for receiving specially designed and patterned $\mathrm{ZnO}$ NW arrays. This approach opens up possibilities to fabricate $\mathrm{ZnO}$ NW array-based strain and force sensors, ${ }^{22,23}$ two-dimensional photonic crystals, integrated circuit interconnects, and alternative current nanogenerators. ${ }^{24,25}$

Acknowledgment. Research supported by DARPA (Army/ AMCOM/REDSTONE AR, W31P4Q-08-1-0009), DARPA STTR with Magnolia Optical Inc., BES DOE (DE-FG02-07ER46394), World Premier International Research Center (WPI) Initiative on Materials Nanoarchitectonics, MEXT, Japan, and Emory-Georgia Tech CCNE from NIH, NSF (DMS 0706436, CMMI 0403671).

Supporting Information Available: Experimental details about the synthesis of the NW arrays and scheme of the strip orientation relative to the substrate. This material is available free of charge via the Internet at http://pubs.acs.org.

\section{References}

(1) Huang, M. H.; Mao, S.; Feick, H.; Yan, H. Q.; Wu, Y. Y.; Kind, H.; Weber, E.; Russo, R.; Yang, P. D. Science 2001, 292, 1897

(2) Sun, X. W.; Huang, J. Z.; Wang, J. X.; Xu, Z. Nano Lett. 2008, 8, 1219.

(3) Bai, X. D.; Wang, E. G.; Gao, P. X.; Wang, Z. L. Nano Lett. 2003, 3, 1147.

(4) Wang, X. D.; Zhou, J.; Lao, C. S.; Song, J. H.; Xu, N. S.; Wang, Z. L. Adv. Mater. 2007, 19, 1627.

(5) Law, M.; Greene, L. E.; Johnson, J. C.; Saykally, R.; Yang, P. D. Nat. Mater. 2005, 4, 455

(6) Wang, Z. L.; Song, J. H. Science 2006, 312, 242.

(7) Wang, X. D.; Song, J. H.; Liu, J.; Wang, Z. L. Science 2007, 316, 102.

(8) Greyson, E. C.; Babayan, Y.; Odom, T. W. Adv. Mater. 2004, 16, 1348.

(9) Wang, X. D.; Summers, C. J.; Wang, Z. L. Nano Lett. 2004, 4, 423.

(10) Liu, D. F.; Xiang, Y. J.; Wu, X. C.; Zhang, Z. X.; Liu, L. F.; Song, L.; Zhao, X. W.; Luo, S. D.; Ma, W. J.; Shen, J.; Zhou, W. Y.; Wang, G.; Wang, C. Y.; Xie, S. S. Nano Lett. 2006, 6, 2375

(11) Hsu, J. W. P.; Tian, Z. R.; Simmons, N. C.; Matzke, C. M.; Voigt, J. A.; Liu, J. Nano Lett. 2005, 5, 83.

(12) Xu, S.; Wei, Y. G.; Kirkham, M.; Liu, J.; Mai, W. J.; Davidovic, D.; Snyder, R. L.; Wang, Z. L. J. Am. Chem. Soc. 2008, 130, 14958.

(13) Qin, Y.; Yang, R. S.; Wang, Z. L. J. Phys. Chem. C 2008, 112, 18734

(14) Conley, J. F.; Stecker, L.; Ono, Y. Appl. Phys. Lett. 2005, 87, 223114.

(15) Chang, S. J.; Hsueh, T. J.; Hsu, C. L.; Lin, Y. R.; Chen, I. C.; Huang, B. R. Nanotechnology 2008, 19, 095505.

(16) Nikoobakht, B.; Michaels, C. A.; Stranick, S. J.; Vaudin, M. D. Appl. Phys. Lett. 2004, 85, 3244.

(17) Park, W. I.; Lee, C. H.; Chae, J. H.; Lee, D. H.; Yi, G. C. Small 2009, 5, 181.

(18) Harnack, O.; Pacholski, C.; Weller, H.; Yasuda, A.; Wessels, J. M. Nano Lett. 2003, 3, 1097.

(19) Vayssieres, L. Adv. Mater. 2003, 15, 464.

(20) Andeen, D.; Kim, J. H.; Lang, F. F.; Goh, G. K. L.; Tripathy, S. Adv. Funct. Mater. 2006, 16, 799

(21) Xu, S.; Lao, C. S.; Weintraub, B.; Wang, Z. L. J. Mater. Res. 2008, 23, 6.

(22) Zhou, J.; Fei, P.; Gao, Y. F.; Gu, Y. D.; Liu, J.; Bao, G.; Wang, Z. L. Nano Lett. 2008, 8, 2725.

(23) Zhou, J.; Gu, Y. D.; Fei, P.; Mai, W. J.; Gao, Y. F.; Yang, R. S.; Bao, G.; Wang, Z. L. Nano Lett. 2008, 8, 3035.

(24) Yang, R. S.; Qin, Y.; Dai, L. M.; Wang, Z. L. Nat. Nanotechnol. 2009, 4, 34.

(25) Yang, R. S.; Qin, Y.; Li, C.; Dai, L. M.; Wang, Z. L. Appl. Phys. Lett. 2009, 94, 022905 .

JA902119H 